\title{
Electrochemical Investigation of Catechol at Poly(niacinamide) Modified Carbon Paste Electrode: A Voltammetric Study
}

\author{
A. B. Teradale, ${ }^{1}$ S. D. Lamani, ${ }^{2}$ B. E. Kumara Swamy, ${ }^{3}$ P. S. Ganesh, ${ }^{3}$ and S. N. Das ${ }^{1}$ \\ ${ }^{1}$ Department of Chemistry, BLDEA's College of Engineering and Technology Affiliated to VTU Belagavi, Vijayapur, Karnataka, India \\ ${ }^{2}$ Department of Chemistry, BLDEA's SB Arts and KCP Science College, Vijayapur, Karnataka, India \\ ${ }^{3}$ Department of PG Studies and Research in Industrial Chemistry, Kuvempu University, Jnana Sahyadri, Shankaraghatta, Shimoga, \\ Karnataka 577451, India
}

Correspondence should be addressed to B. E. Kumara Swamy; kumaraswamy21@yahoo.com

Received 19 July 2016; Revised 20 September 2016; Accepted 4 October 2016

Academic Editor: Claudio Fontanesi

Copyright (C) 2016 A. B. Teradale et al. This is an open access article distributed under the Creative Commons Attribution License, which permits unrestricted use, distribution, and reproduction in any medium, provided the original work is properly cited.

A polymeric thin film modified electrode, that is, poly(niacinamide) modified carbon paste electrode (MCPE), was developed for the electrochemical determination of catechol (CC) by using cyclic voltammetric technique. Compared to bare carbon paste electrode (BCPE), the poly(niacinamide) MCPE shows good electrocatalytic activity towards the oxidation of catechol in phosphate buffer solution (PBS) of physiological pH 7.4. All experimental parameters were optimized. Poly(niacinamide) modified carbon paste electrode gave a linear response between concentration of CC and its anodic peak current in the range within 20.6-229.0 $\mu \mathrm{M}$. The limit of detection $(3 \mathrm{~S} / \mathrm{M})$ and limit of quantification $(10 \mathrm{~S} / \mathrm{M})$ were $1.497 \mu \mathrm{M}$ and $4.99 \mu \mathrm{M}$, respectively. From the study of scan rate variation, the electrode process was found to be adsorption-controlled. The involvement of protons and electrons in the oxidation of CC was found to be equal. The probable electropolymerisation mechanism of niacinamide was proposed. Finally, this method can be used in development of a sensor for sensitive determination of CC.

\section{Introduction}

Electrochemically controlled formation of thin polymer films at surface of the electrode is one of the sensible techniques to determine new functional active species. Their uses as a monomer or a polymer for modification of several electrodes have been increasingly used in analytical applications [1]. Catechol (CC), that is also known as pyrocatechol or 1,2dihydroxybenzene, is a simple organic compound as shown in Scheme 1. It is a natural polyphenolic compound that extensively exists in higher plants such as tea and vegetables and it can be released to the environment during its manufacture and use. It has a biological significance such as antioxidation and antiviral, flower stimulating effect and affecting the activities of some enzymes [2-4]. Even in a very low concentration, these isomers are very toxic to animals and human beings and they are difficult to degrade. Because of this fact, they are the major problem and cause for the environment pollution [5].
An assessment of the literature revealed that there are only rare analytical methods for the determination of CC, such as clay-modified electrode [6], multiwalled carbon nanotubes modified glassy carbon electrode [7], iodine-coated polycrystalline platinum electrode [8], bare indium tin oxide electrodes [9], poly(brilliant blue) modified carbon paste electrode [10], electrochemiluminescence [3], DL-norvaline modified glassy carbon electrode [11], anthraquinone modified carbon paste electrode [12], screen printed graphite electrode [13], and p-aminosalicylic acid and multiwall carbon nanotubes composite film modified glassy carbon [14] method.

Cyclic voltammetry (CV) is a powerful analytical technique that provides information about the undergoing characteristic electrochemical processes of an analyte in solution, which is used to diagnose mechanisms of electrochemical reactions, for detection of the species present in solution [15]. Several electrodes mainly carbon paste electrodes play an important role in electrochemical investigations because 
<smiles>Oc1ccccc1O</smiles>

Scheme 1: Structure of catechol.<smiles>NC(=O)c1cccnc1</smiles>

SCHEME 2: Structure of niacinamide.

of their low background current, low cost, and renewability with many electron mediators [16]. In the literature, poly(niacinamide) modified glassy carbon electrode exhibited several excellent electrochemical properties and high electrochemical stability towards the oxidation of dopamine. These properties enable the poly(niacinamide) glassy carbon electrode to render good reproducibility [17].

Niacinamide is one of the derivatives of pyridine and readily soluble in water. It is also a main constituent of B-vitamin, required for mammalian daily diet. Due to its significant biological activity, it is widely investigated over the last few decades [18]. The chemical structure of niacinamide is shown in Scheme 2. The present work describes the electropolymerisation of niacinamide on the surface of the carbon paste electrode for the electrochemical investigation of $\mathrm{CC}$ by $\mathrm{CV}$ technique.

The CV response of CC at modified electrode shows some major advantages like high sensitivity, stability, reproducibility, and comparatively lower detection limit. Overall, the modification procedure reported in this article was modest, efficient, and sensitive in the electrochemical detection of CC.

\section{Experimental}

2.1. Instrumentation. Electrochemical studies were carried out by using an electrochemical work station CHI-660c (CH Instrument-660 electrochemical analyser) coupled with a conventional three-electrode cell comprised of saturated calomel electrode (SCE) as a reference, a platinum wire as a counter electrode, and bare carbon paste electrode (BCPE) or poly(niacinamide) modified carbon paste electrode (MCPE) as working electrode. All the voltammograms were recorded at an ambient temperature of $25 \pm 0.2^{\circ} \mathrm{C}$. The corresponding oxidation potential of analytes was recorded versus SCE.

2.2. Reagents and Chemicals. All chemicals were of analytical grade and used without additional purification. Catechol (CC) was purchased from Himedia (molecular weight $=110.1$, purity 99\%). Niacinamide was obtained from Sigma Ltd., India (molecular weight $=122.12$, purity 99.5\%). A stock solution of CC $\left(25 \times 10^{-4} \mathrm{M}\right)$ was prepared by dissolving in double distilled water $(18 \mathrm{M} \Omega \mathrm{cm})$. Phosphate buffer solution (PBS) of same ionic strength was prepared $(0.2 \mathrm{M})$ by mixing appropriate ratio of $\mathrm{NaH}_{2} \mathrm{PO}_{4} \cdot \mathrm{H}_{2} \mathrm{O}$ and $\mathrm{Na}_{2} \mathrm{HPO}_{4}$. Graphite powder of average particle size $50 \mu \mathrm{M}$ was purchased from Merck and silicon oil from Himedia was used to prepare carbon paste electrode (CPE). All other reagents used were of analytical grade. All solutions were prepared with double distilled water.

2.3. Preparation of Bare Carbon Paste Electrode. The BCPE was prepared by hand mixing of $70 \%$ graphite powder and $30 \%$ silicone oil in an agate mortar and grinded for about 45 min until a homogeneous paste was formed. The paste was packed into a homemade cavity of Teflon tube of $3 \mathrm{~mm}$ internal diameter and the surface was smoothened on a weighing paper. Unless otherwise stated, the paste was carefully removed prior to pressing a new portion into the electrode after every measurement. The electrical contact was provided by a copper wire connected to the end of the tube.

2.4. Preparation of Poly(niacinamide) MCPE. Electrochemical polymerisation of niacinamide at the BCPE was carried out using cyclic voltammetric technique. The BCPE was scanned for 10 multiple cycles in an electrochemical cell containing aqueous solution of $1 \mathrm{mM}$ niacinamide monomer in $0.2 \mathrm{M}$ PBS of $\mathrm{pH}$ 7.4. The electropolymerisation was achieved by successive cyclic voltammetric sweep between $-0.8 \mathrm{~V}$ and $+1.8 \mathrm{~V}$ with the scan rate of $0.1 \mathrm{Vs}^{-1}$. After that, the polymeric thin film modified electrode, that is, poly(niacinamide) MCPE, was rinsed thoroughly with double distilled water and used for the determination of CC.

\section{Result and Discussion}

3.1. Electrochemical Polymerisation of Niacinamide on BCPE. The poly(niacinamide) MCPE was fabricated by CV technique in between the potential window $-0.8 \mathrm{~V}$ to $+1.8 \mathrm{~V}$ with scan rate $0.1 \mathrm{Vs}^{-1}$ for 10 multiple cycles in $0.2 \mathrm{M}$ PBS of pH 7.4 until a stable cyclic voltammogram was obtained. In this process of multiple cycles, the voltammogram was slowly descended with increasing in cyclic times as shown in Figure 1. This indicates that the niacinamide layer was formed and deposited on BCPE. The thickness of the layer also affects the electrocatalytic property of the electrode and it can be maintained by changing the sweep segments. The probable mechanism of electropolymerisation of niacinamide is described in Scheme 3. Such types of mechanisms have been proposed in earlier report [11].

3.2. Characterization of Poly (niacinamide) MCPE. Figure 2 shows the CV responses recorded for the oxidation of $1 \mathrm{mM}$ potassium ferrocyanide in $1 \mathrm{M} \mathrm{KCl}$ as a supporting electrolyte with the scan rate $0.05 \mathrm{Vs}^{-1}$. The voltammograms obtained at BCPE (dashed line) were with less sensitivity. However, on the other hand, voltammogram obtained at poly(niacinamide) MCPE (solid line) shows remarkable improvement in the electrotransfer process. The improved result obtained for the voltammetric response of potassium ferrocyanide at poly(niacinamide) MCPE confirms that the surface morphology was significantly changed and also result proves 


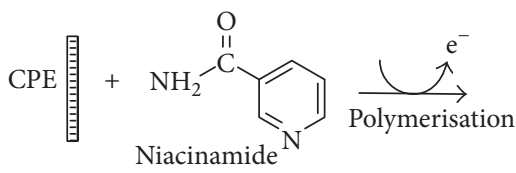

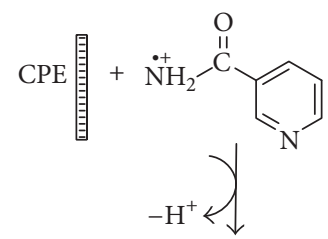

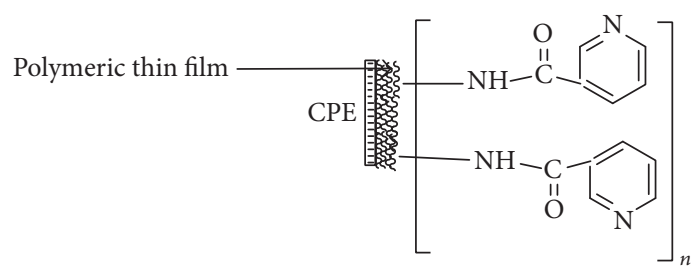

Poly(niacinamide) MCPE

Scheme 3: Mechanism of electropolymerisation of niacinamide on the surface of BCPE.

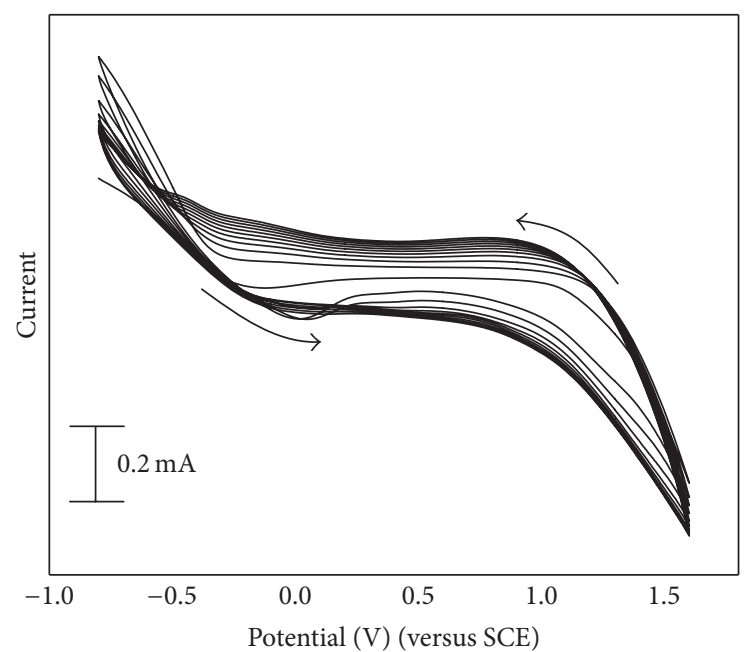

FIGURE 1: Cyclic voltammograms of preparation of poly(niacinamide) MCPE and $1.0 \mathrm{mM}$ of aqueous solution of niacinamide in $0.2 \mathrm{M}$ $\mathrm{PBS}$ of $\mathrm{pH} 7.4$ at 10 cycles with scan rate of $0.1 \mathrm{Vs}^{-1}$.

electrocatalytic activity of the poly(niacinamide) MCPE. The total active surface area available for reaction of species in solution can be estimated by the Randles-Sevcik equation (1) $[1,19]$ :

$$
I_{\mathrm{p}}=2.69 \times 10^{5} n^{3 / 2} A D^{1 / 2} C_{0} v^{1 / 2}
$$

where $I_{\mathrm{p}}$ is the peak current in A. $C_{0}$ is the concentration of the electroactive species $\left(\mathrm{mol} \mathrm{cm}^{-3}\right), n$ is the number of electrons exchanged, $D$ is the diffusion-coefficient $(9.196 \times$ $\left.10^{-4} \mathrm{~cm}^{2} \mathrm{~s}^{-1}\right), v$ is the scan rate $\left(\mathrm{Vs}^{-1}\right)$, and $A$ is the electroactive surface area $\left(\mathrm{cm}^{2}\right)$. For poly(niacinamide) MCPE, the electroactive surface area is maximum $\left(0.0412 \mathrm{~cm}^{2}\right)$ as compared with bare CPE $\left(0.0288 \mathrm{~cm}^{2}\right)$.

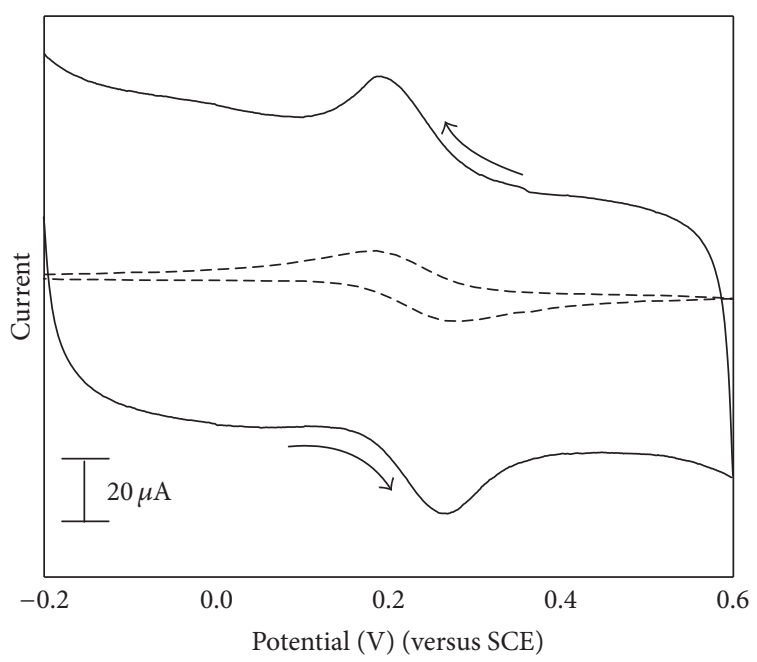

FIGURE 2: Cyclic voltammograms of $1.0 \mathrm{mM}$ potassium ferrocyanide at BCPE (dashed line) and poly(niacinamide) MCPE (solid line) at scan rate of $0.05 \mathrm{Vs}^{-1}$.

An approximate surface coverage of the poly(niacinamide) layer formed on the surface of carbon paste electrode (CPE) was calculated by $[15,20]$

$$
I_{\mathrm{p}}=\frac{n^{2} F^{2} A \Gamma v}{4 R T},
$$

where $\Gamma\left(\mathrm{M} / \mathrm{cm}^{2}\right)$ represents the surface coverage concentration which is proportional to the peak current $\left(I_{\mathrm{p}}\right), v$ is the scan rate, $A$ is the geometric surface area of the electrode, $n$ is the number of electrons involved in the reaction, and $R, F, T$ have their usual significance. The surface coverage of poly(niacinamide) adhered on the surface of CPE was determined to be $0.0476 \times 10^{-10} \mathrm{M} / \mathrm{cm}^{2}$.

3.3. Electrochemical Response of CC at Poly(niacinamide) $M C P E$. Figure 3 shows the cyclic voltammograms of $0.2 \mathrm{mM}$ 


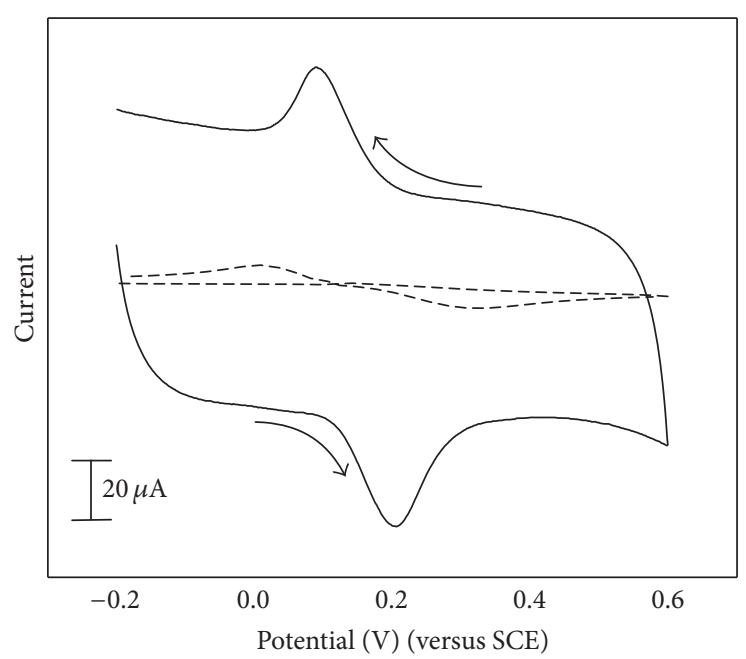

FIGURE 3: Cyclic voltammograms for $0.2 \mathrm{mM} \mathrm{CC}$ at BCPE (dashed line) and poly(niacinamide) MCPE (solid line) in $0.2 \mathrm{M}$ PBS of pH 7.4 at scan rate $0.05 \mathrm{Vs}^{-1}$.

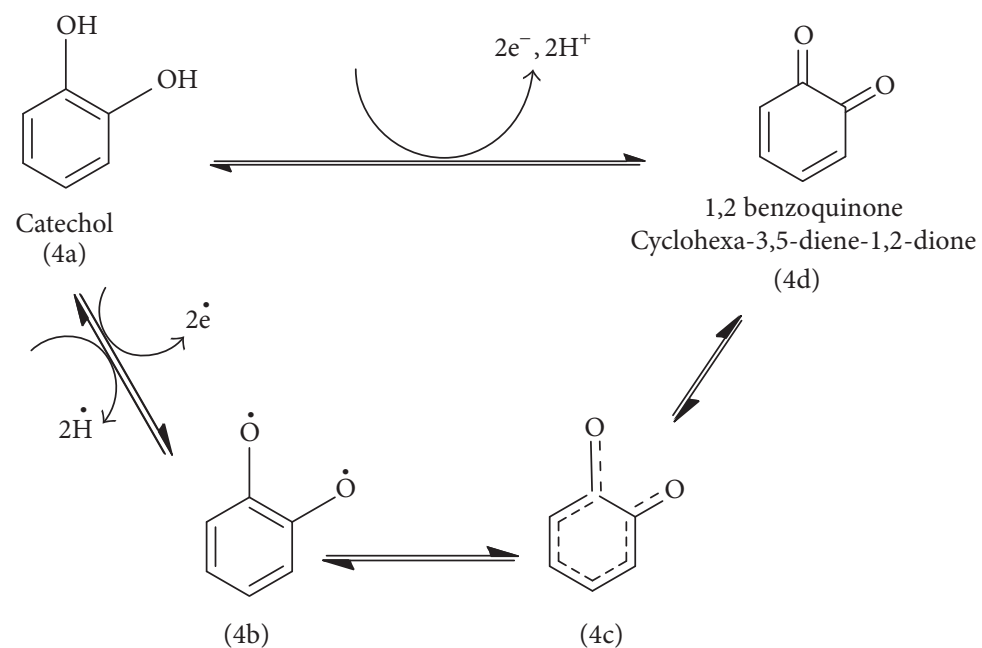

SCHEME 4: Oxidation mechanism of catechol (CC).

$\mathrm{CC}$ at BCPE and poly(niacinamide) MCPE in 0.2 M PBS of $\mathrm{pH} 7.4$ with the scan rate $0.05 \mathrm{Vs}^{-1}$. At BCPE, catechol shows a poor voltammetric response due to slow electron transport phenomenon, and the oxidation peak potential occurred at $0.322 \mathrm{~V}$ versus SCE. On the other hand, poly(niacinamide) MCPE showed great increment in current signals and the oxidation peak potential was observed at $0.204 \mathrm{~V}$. This minimisation of overpotential and enhancement of current response confirms electrocatalytic activity of poly(niacinamide) MCPE towards the electrochemical oxidation of CC [10].

In this proposed method, the oxidation steps of CC were located on benzene ring containing two hydroxyl groups, which represents a typical redox system with twoelectron oxidation process taking place. In this mechanism, CC (4a) loses two electrons and also loses two protons, forming a cation radical (4b), which further takes place in delocalization of electron (4c). Thus, the resulting 1,2benzoquinone or cyclohexa-3,5-diene-1,2-dione compound was formed (4d). The mechanism is shown in Scheme 4. Such types of mechanism have been proposed in earlier reports $[21,22]$.

3.4. Effect of Scan Rate on the Peak Current of CC. The effect of scan rate for the oxidation of $0.2 \mathrm{mM} \mathrm{CC}$ in $0.2 \mathrm{M}$ PBS of $\mathrm{pH}$ 7.4 was studied by CV technique at poly(niacinamide) MCPE. According to Randles-Sevcik equation, the peak current is directly proportional to scan rate. Figure 4(a) shows the increase of anodic peak currents with increase in scan rate with good linearity in the range from $0.025 \mathrm{Vs}^{-1}$ to $0.2 \mathrm{Vs}^{-1}$. The plot of peak current $\left(I_{\mathrm{p}}\right)$ versus scan rate $(v)$ and $I_{\mathrm{p}}$ versus square root scan rate $\left(v^{1 / 2}\right)$ was plotted, which gives a straight line with good linearity. A good correlation coefficient $\left(r^{2}\right)$ was observed between $I_{\mathrm{p}}$ and $v^{1 / 2}$ with the values 0.9974 and 0.9966 as shown in Figures 4(b) and 4(c). This result suggests that the electrode phenomenon was diffusion controlled process $[23,24]$. 


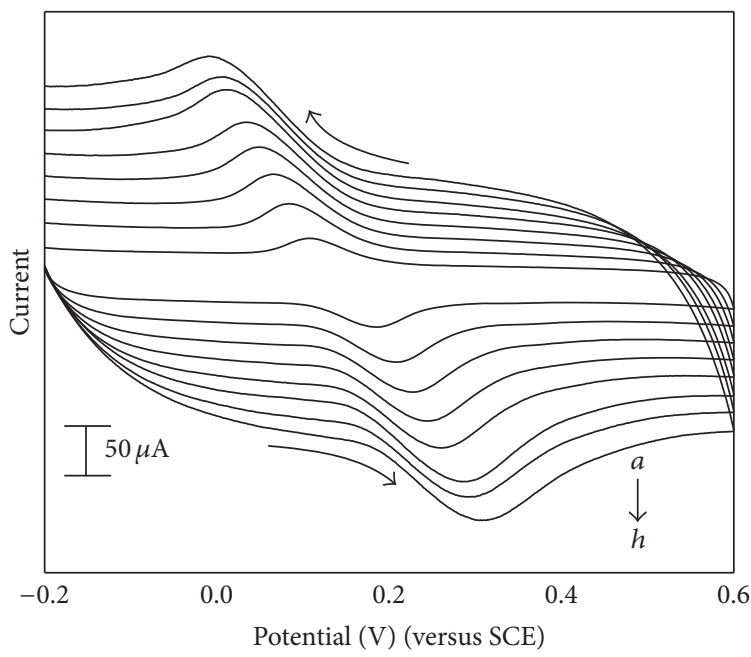

(a)

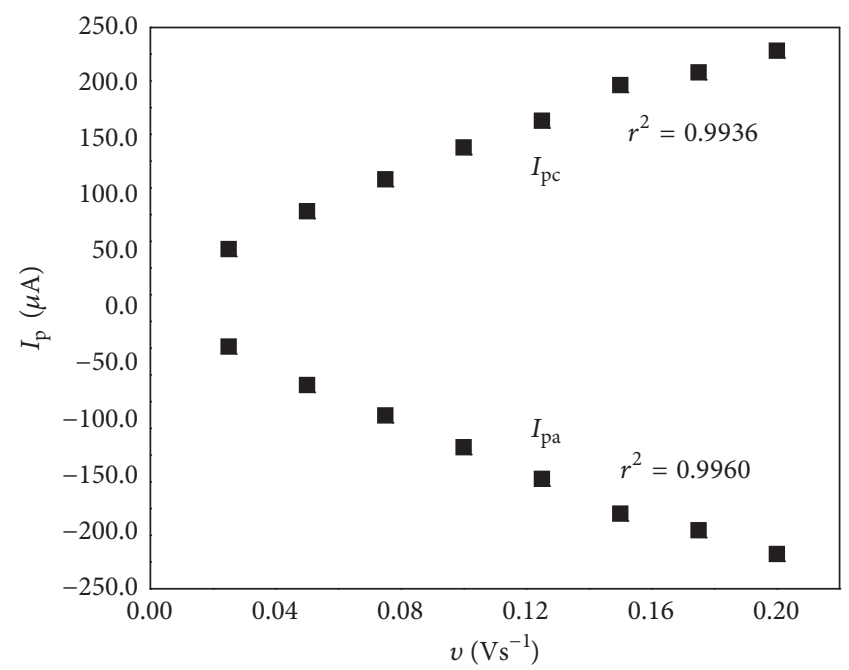

(b)

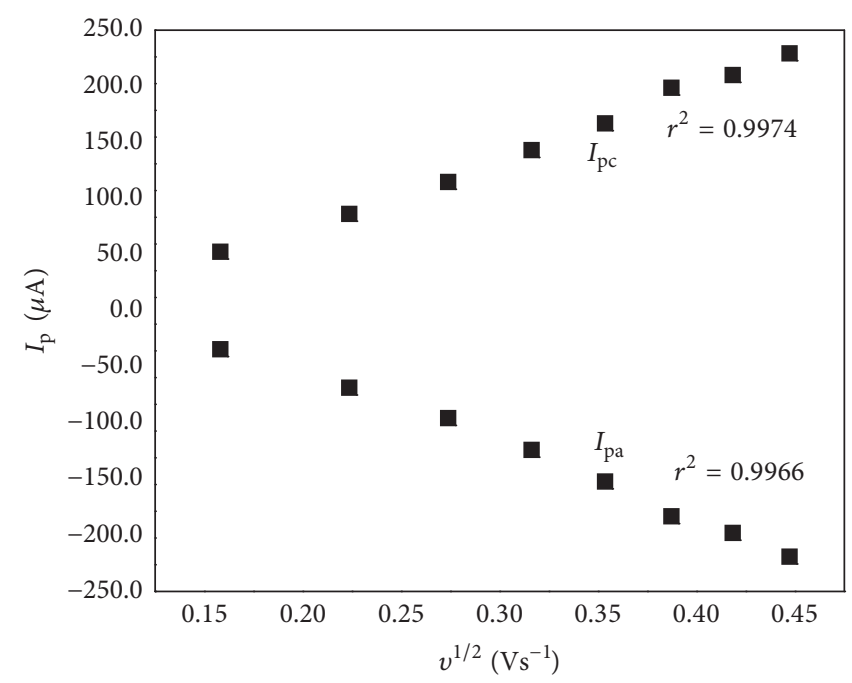

(c)

Figure 4: (a) Cyclic voltammograms for $0.2 \mathrm{mM} \mathrm{CC}$ at poly(niacinamide) MCPE in $0.2 \mathrm{M}$ PBS of pH 7.4 at different scan rate $\left(a-h\right.$; $0.025 \mathrm{Vs}{ }^{-1}$, $0.05 \mathrm{Vs}^{-1}, 0.075 \mathrm{Vs}^{-1}, 0.1 \mathrm{Vs}^{-1}, 0.125 \mathrm{Vs}^{-1}, 0.15 \mathrm{Vs}^{-1}, 0.175 \mathrm{Vs}^{-1}$, and $\left.0.2 \mathrm{Vs}^{-1}\right)$. (b) The graph of peak current $\left(I_{\mathrm{p}}\right)$ versus scan rate $(v)$. (c) The graph of peak current $\left(I_{\mathrm{p}}\right)$ versus square root of scan rate.

3.5. Effect of $p H$ Value on the Determination of CC at Poly(niacinamide) MCPE. The effect of solution $\mathrm{pH}$ has a significant contribution on the electrochemical oxidation and was carefully investigated by CV technique. Figure 5(a) shows the dependence of the $\mathrm{CV}$ responses of $0.2 \mathrm{mM} \mathrm{CC}$ at poly(niacinamide) MCPE in the $\mathrm{pH}$ range of 6.0-8.0. The result shows that, by increasing the $\mathrm{pH}$ of $0.2 \mathrm{mM}$ $\mathrm{PBS}$, the oxidation potential was shifted to more negative potential side. The anodic peak potential $\left(E_{\mathrm{pa}}\right)$ versus $\mathrm{pH}$ graph clearly indicates that the catalytic oxidation potential depends linearly on the $\mathrm{pH}$ with a slope of $0.0558 \mathrm{~V} / \mathrm{pH}\left(r^{2}\right.$ $=0.9995)$ as shown in Figure 5(b). This signifies that there is an involvement of equal number of protons and electrons in the redox mechanism according to Nernst equation. This was consistent with the earlier report $[10,22,24,25]$.
3.6. Effect of CC Concentration. The electro oxidation of CC was carried out by varying its concentration at poly(niacinamide) MCPE from $20.6 \mu \mathrm{M}$ to $229.0 \mu \mathrm{M}$ in $0.2 \mathrm{M}$ PBS of pH 7.4 at scan rate $0.05 \mathrm{Vs}^{-1}$ as shown in Figure 6(a). By increasing the concentration of catechol, $I_{\mathrm{pa}}$ goes on increasing with shifting $E_{\mathrm{pa}}$ towards positive side. The graph of $I_{\mathrm{pa}}$ versus concentration of CC justifies the reason of increase in anodic peak current, which is due to increase in the concentration of CC as shown in Figure 6(b). The graph shows almost straight line with good linearity with detection and quantification limit of $1.497 \mu \mathrm{M}$ and $4.99 \mu \mathrm{M}$, respectively, for CC at poly(niacinamide) MCPE. The detection limits reported for different classical methods and electrodes are tabulated in Table 1. This method was good compared to other reported methods [9, 11, 26-28]. 
TABLE 1: Comparison of linear range and detection limits for catechol with different classical methods and electrodes.

\begin{tabular}{|c|c|c|c|c|}
\hline Classical methods & Electrode/modifier biosensors & Detection limits $(\mu \mathrm{M})$ & Detection Potential (V) & Refs. \\
\hline $\mathrm{DPV}$ & Bare indium tin oxide electrode & 1.0 & 0.26 & [9] \\
\hline DPV & DL-norvaline modified GCE & 0.8 & 0.37 & [11] \\
\hline DPV & {$[\mathrm{Cu}(\mathrm{Sal}-\beta-\mathrm{Ala})(3,5-\mathrm{DMPz}) 2] / \mathrm{SWCNTs} / \mathrm{GCE}$} & 1.46 & 0.07 & [26] \\
\hline DPV & $\begin{array}{c}\text { GCE/with a composite consisting of silver } \\
\text { nanoparticles (AgNPs), polydopamine, and graphene }\end{array}$ & 0.1 & - & [27] \\
\hline DPV & PASA/MWNTs composite film modified GCE & 1.0 & - & {$[28]$} \\
\hline $\mathrm{CV}$ & Poly-NA modified CPE & 1.49 & 0.20 & Present work \\
\hline
\end{tabular}

DPV: differential pulse voltammetry; CV: cyclic voltammetry; GCE: glassy carbon electrode; Sal: salicylaldehyde; $\beta$-Ala: $\beta$-alanine; 3,5-DMPz: 3,5dimethylpyrazole: SWCNTs: single-walled carbon nanotubes; PASA/MWNTs: polyamidosulfonic acid and multiwall carbon nanotubes.

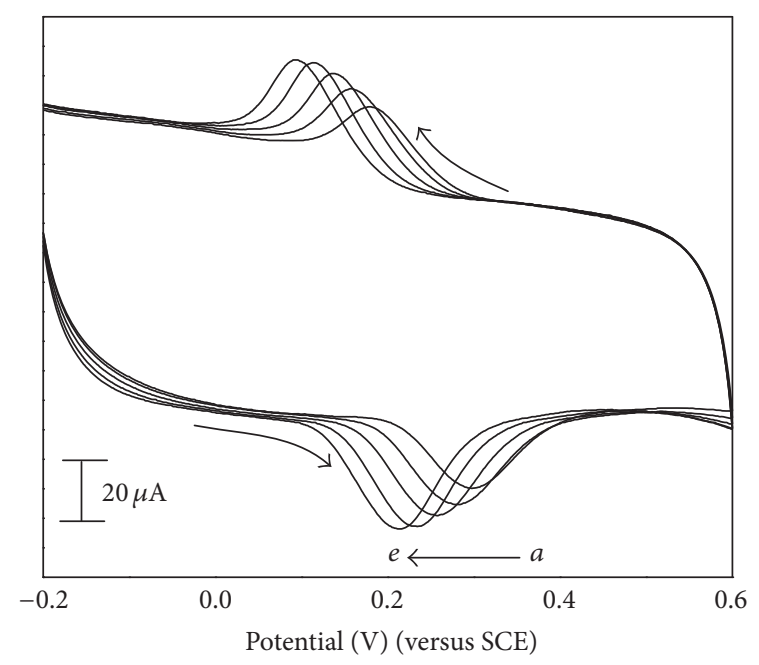

(a)

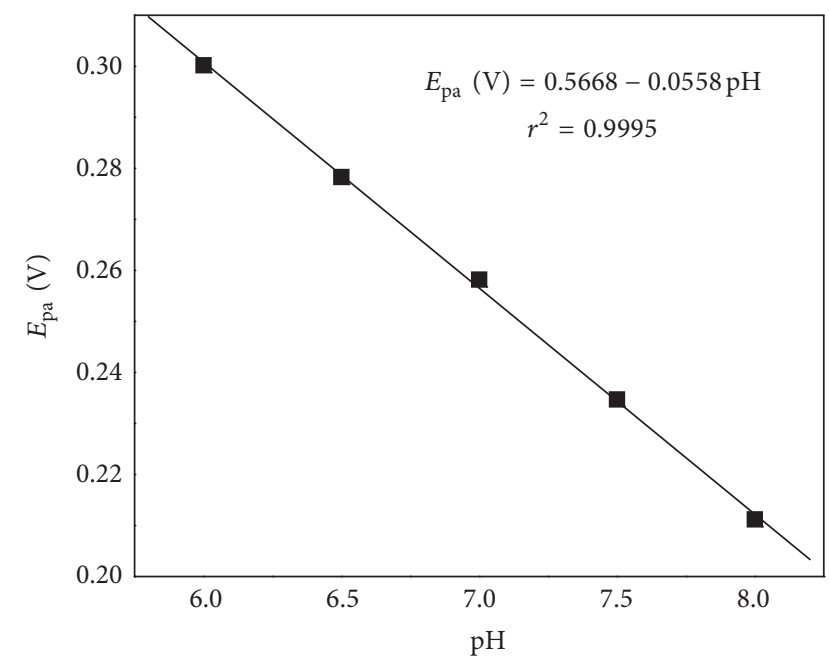

(b)

FIGURE 5: (a) Cyclic voltammograms of $0.2 \mathrm{mM}$ CC at poly(niacinamide) MCPE in $0.2 \mathrm{M}$ PBS solution of different $\mathrm{pH}$ values (a-e: 6.0 to 8.0) at scan rate of $0.05 \mathrm{Vs}^{-1}$. (b) The effect of $\mathrm{pH}$ on the peak potential response of CC.

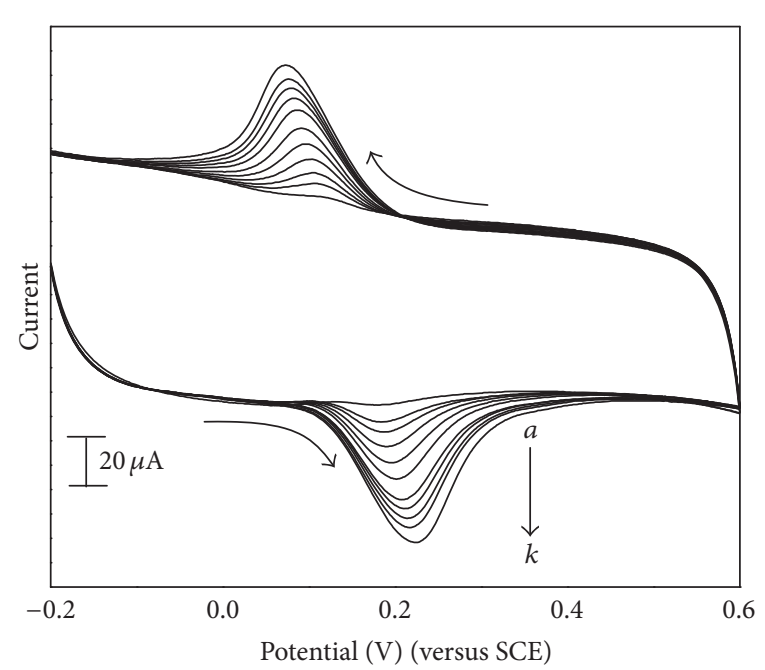

(a)

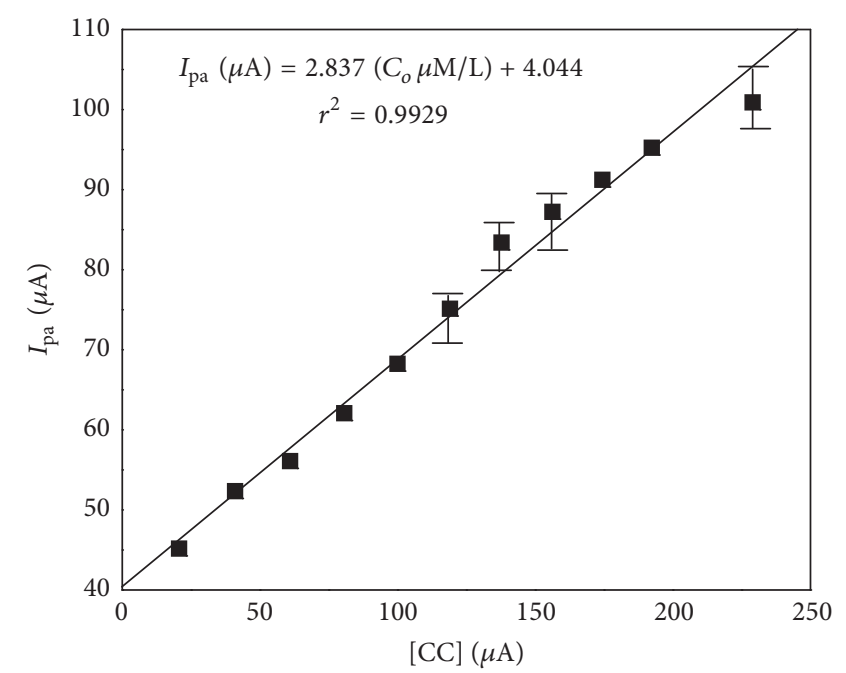

(b)

Figure 6: (a) Cyclic voltammograms of CC in $0.2 \mathrm{M}$ PBS solution of $\mathrm{pH} 7.4$ at poly(niacinamide) MCPE at scan rate of $0.05 \mathrm{Vs}^{-1}$ with different concentrations ( $a-k$ : $20.6 \mu \mathrm{M}, 40.9 \mu \mathrm{M}, 60.9 \mu \mathrm{M}, 80.6 \mu \mathrm{M}, 100.0 \mu \mathrm{M}, 119.0 \mu \mathrm{M}, 137.7 \mu \mathrm{M}, 156.2 \mu \mathrm{M}, 174.4 \mu \mathrm{M}, 192.3 \mu \mathrm{M}$, and $229.0 \mu \mathrm{M})$. (b) Graph of anodic peak current versus concentration of CC. 


\section{Conclusion}

In the present work the poly(niacinamide) MCPE was fabricated for the electrooxidation of $\mathrm{CC}$ in $\mathrm{PBS}$ of $\mathrm{pH} 7.4$ by $\mathrm{CV}$ technique. The modified electrode shows a detection and quantification limit of $1.497 \mu \mathrm{M}$ and $4.99 \mu \mathrm{M}$, respectively. The sensitivity, stability, and reproducibility were shown by the modified electrode. Overall, a simple modification procedure was reported for the determination of catechol by cyclic voltammetric technique.

\section{Competing Interests}

The authors declare that there are no competing interests regarding the publication of this paper.

\section{Acknowledgments}

The authors wish to express their gratitude to the Department of Science and Technology and Science and Engineering Research Board, Ref. no. SERB/F/1217/2014-15, Dated 28-052014, New Delhi, for financial support of this work.

\section{References}

[1] P. S. Ganesh and B. E. K. Swamy, "Simultaneous electroanalysis of norepinephrine, ascorbic acid and uric acid using poly(glutamic acid) modified carbon paste electrode," Journal of Electroanalytical Chemistry, vol. 752, pp. 17-24, 2015.

[2] P. A. Kilmartin and C. F. Hsu, "Characterisation of polyphenols in green, oolong, and black teas, and in coffee, using cyclic voltammetry," Food Chemistry, vol. 82, no. 4, pp. 501-512, 2003.

[3] Y.-G. Sun, H. Cui, Y.-H. Li, and X.-Q. Lin, "Determination of some catechol derivatives by a flow injection electrochemiluminescent inhibition method," Talanta, vol. 53, no. 3, pp. 661-666, 2000.

[4] A. Kiani, J.-B. Raoof, D. Nematollahi, and R. Ojani, "Electrochemical study of catechol in the presence of dibuthylamine and diethylamine in aqueous media: part 1. Electrochemical investigation," Electroanalysis, vol. 17, no. 19, pp. 1755-1760, 2005.

[5] X. Li, G. Xu, X. Jiang, and J. Tao, "Highly sensitive and simultaneous determination of hydroquinone and catechol at thionine/graphene oxide modified glassy carbon electrodes," Journal of the Electrochemical Society, vol. 161, no. 9, pp. H464H468, 2014.

[6] J.-M. Zen and P.-J. Chen, "An ultrasensitive voltammetric method for dopamine and catechol detection using claymodified electrodes," Electroanalysis, vol. 10, no. 1, pp. 12-15, 1998.

[7] H. Qi and C. Zhang, "Simultaneous determination of hydroquinone and catechol at a glassy carbon electrode modified with multiwall carbon nanotubes," Electroanalysis, vol. 17, no. 10, pp. 832-838, 2005.

[8] K. H. Mohammed and H. Bushra, "Voltammetric analysis of hydroquinone and catechol at iodine-coated polycrystalline platinum electrode," International Journal of Natural and Engineering Sciences, vol. 8, pp. 25-29, 2014.

[9] M. Abdul Aziz, T. Selvaraju, and H. Yang, "Selective determination of catechol in the presence of hydroquinone at bare indium tin oxide electrodes via peak-potential separation and redox cycling by hydrazine," Electroanalysis, vol. 19, no. 14, pp. 15431546, 2007.

[10] P. S. Ganesh and B. E. Kumara Swamy, "Simultaneous electroanalysis of hydroquinone and catechol at poly(brilliant blue) modified carbon paste electrode: A Voltammetric Study," Journal of Electroanalytical Chemistry, vol. 756, pp. 193-200, 2015.

[11] M. M. Kamel, "Electrooxidation of DL-norvaline at Glassy Carbon Electrode: approaching the modified electrode for voltammetric studies of hydroquinone and catechol," Journal of Electrochemical Science and Technology, vol. 5, no. 1, pp. 23-31, 2014.

[12] F. Melak, M. Redi, M. Tessema, and E. Alemayehu, "Electrochemical determination of catechol in tea samples using anthraquinone modified carbon paste electrode," Natural Science, vol. 05, no. 08, pp. 888-894, 2013.

[13] A. M. M. Gaber, "Electrochemical sensor for voltammetric determination of catechol based on screen printed graphite electrode," International Journal of Electrochemical Science, vol. 4, pp. 1167-1177, 2009.

[14] A. Yazachew, A. Meareg, A. Shimelis, and T. Merid, "Simultaneous Determination of hydroquinone and catechol at poly(pASA)/MWNTs composite film modified glassy carbon electrode," Ethiopian Journal of Science, vol. 35, no. 1, pp. 29-40, 2012.

[15] S. Chitravathi, B. E. Kumara Swamy, G. P. Mamatha, and B. S. Sherigara, "Electrochemical behavior of poly (naphthol green B)-film modified carbon paste electrode and its application for the determination of dopamine and uric acid," Journal of Electroanalytical Chemistry, vol. 667, pp. 66-75, 2012.

[16] M. A. El Mhammedi, M. Bakasse, and A. Chtainia, "Squarewave voltammetric determination of paraquat at carbon paste electrode modified with hydroxyapatite," Electroanalysis, vol. 19, no. 16, pp. 1727-1733, 2007.

[17] X. Zhu and X. Lin, "Eletropolymerization of niacinamide for fabrication of electrochemical sensor: simultaneous determination of dopamine, uric acid and ascorbic acid," Chinese Journal of Chemistry, vol. 27, no. 6, pp. 1103-1109, 2009.

[18] K. L. Rahman, M. A. Mamun, and M. Q. Ehsan, "Preparation of metal Niacin complexes and characterization using spectroscopic and electrochemical techniques," Russian Journal of Inorganic Chemistry, vol. 56, no. 9, pp. 1436-1442, 2011.

[19] A. J. Bard and L. R. Faulkner, Electrochemical Methods: Fundamentals and Applications, John Wiley \& Sons, New York, NY, USA, 2nd edition, 2001.

[20] J. Wang, Analytical Electrochemistry, VCH Publishers, New York, NY, USA, 1994

[21] A. Ahmad, Y. Wei, F. Syed et al., "Size dependent catalytic activities of green synthesized gold nanoparticles and electrocatalytic oxidation of catechol on gold nanoparticles modified electrode," RSC Advances, vol. 5, no. 120, pp. 99364-99377, 2015.

[22] P. Ganesh and B. K. Swamy, "Voltammetric resolution of catechol and hydroquinone at eosin Y film modified carbon paste electrode," Journal of Molecular Liquids, vol. 220, pp. 208215, 2016.

[23] P. S. Ganesh and B. E. K. Swamy, "Voltammetric resolution of dopamine in presence of ascorbic acid and uric acid at poly (Brilliant Blue) modified carbon paste electrode," Journal of Analytical \& Bioanalytical Techniques, vol. 6, article 229, 2015.

[24] P. S. Ganesh and B. E. K. Swamy, "Cyclic voltammetric determination of catechol and hydroquinone at TX-100 modified 
carbon paste electrode," Analytical \& Bioanalytical Electrochemistry, vol. 8, no. 5, pp. 615-628, 2016.

[25] P. S. Ganesh, B. E. Kumara Swamy, and Rekha, "Electroanalysis of catechol in presence of hydroquinone at poly (calmagite) modified carbon paste electrode: a voltammetric study," Science Letters Journal, vol. 5, article 236, 2016.

[26] L. A. Alshahrani, X. Li, H. Luo et al., "The simultaneous electrochemical detection of catechol and hydroquinone with $\left[\mathrm{Cu}\left(\mathrm{Sal}-\beta\right.\right.$-Ala)(3,5-DMPz) $\left.{ }_{2}\right] /$ SWCNTs/GCE," Sensors, vol. 14, no. 12, pp. 22274-22284, 2014.

[27] K.-J. Huang, L. Wang, J. Li, M. Yu, and Y.-M. Liu, "Electrochemical sensing of catechol using a glassy carbon electrode modified with a composite made from silver nanoparticles, polydopamine, and graphene," Microchimica Acta, vol. 180, no. 9-10, pp. 751-757, 2013.

[28] D.-M. Zhao, X.-H. Zhang, L.-J. Feng, L. Jia, and S.-F. Wang, "Simultaneous determination of hydroquinone and catechol at PASA/MWNTs composite film modified glassy carbon electrode," Colloids and Surfaces B: Biointerfaces, vol. 74, no. 1, pp. 317-321, 2009. 

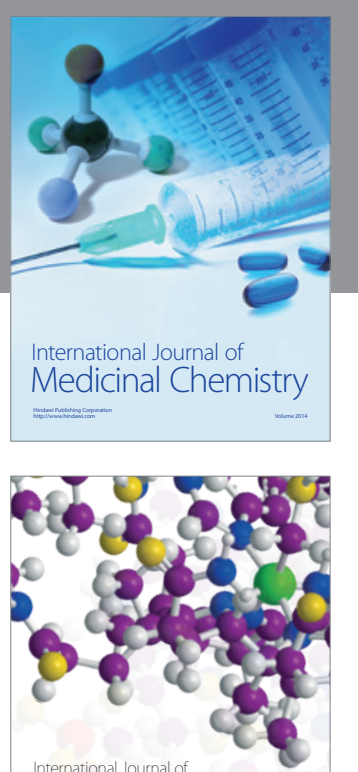

Carbohydrate Chemistry

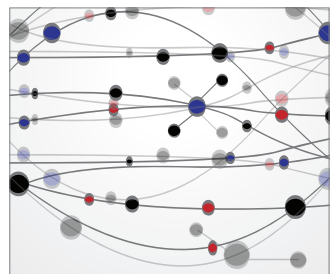

The Scientific World Journal
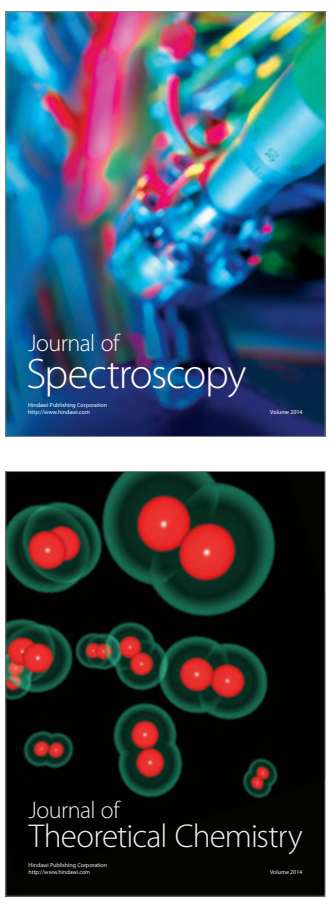
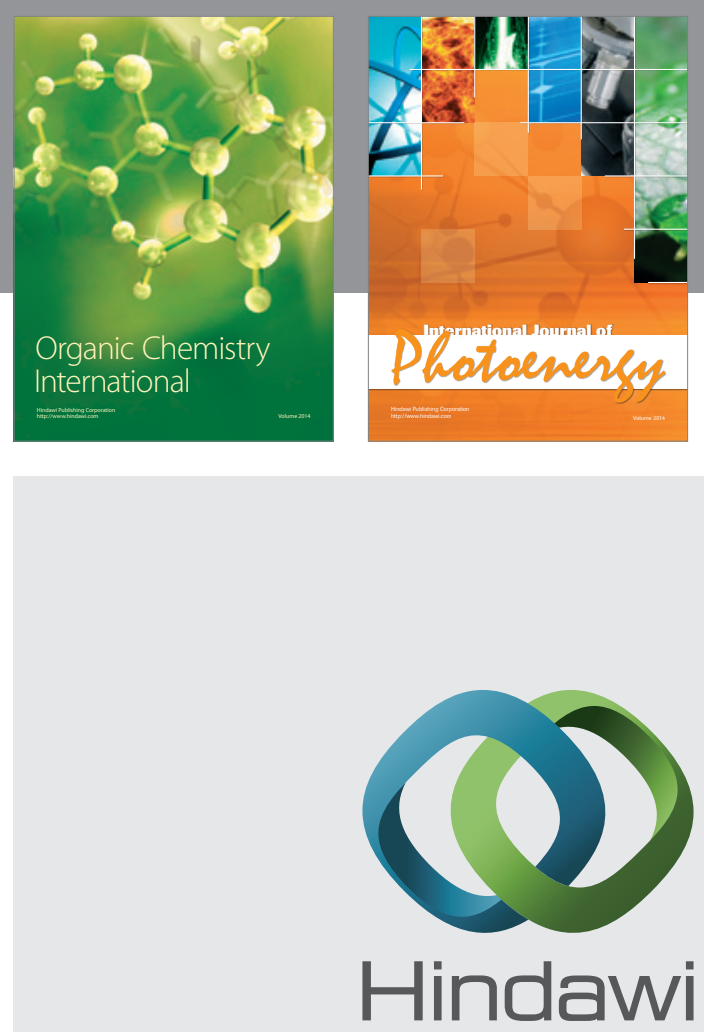

Submit your manuscripts at

http://www.hindawi.com

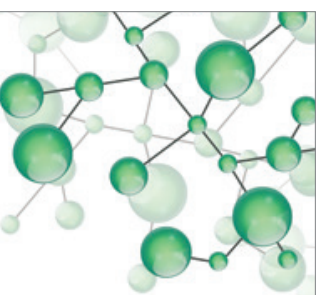

International Journal of

Inorganic Chemistry

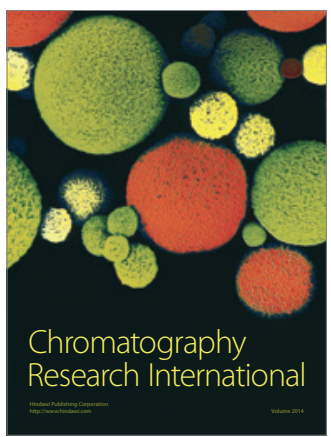

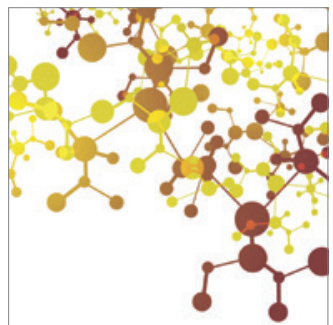

Applied Chemistry
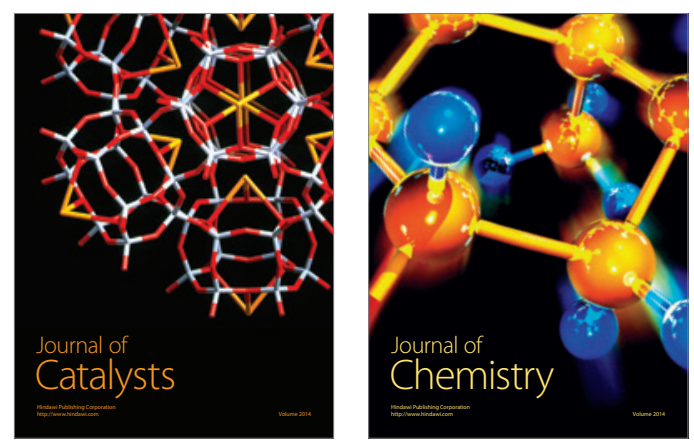
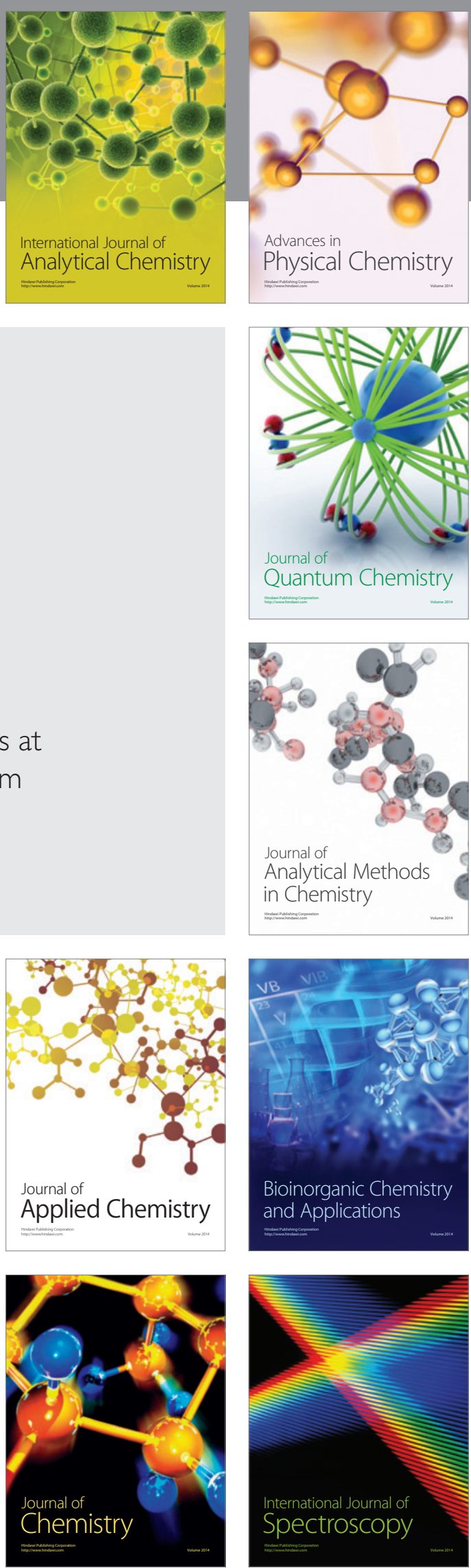